\title{
Marula Oil and Petrodiesel: A Comparative Performance Analysis on a Variable Compression Ignition Engine
}

\author{
Jerekias Gandure, Clever Ketlogetswe \\ Department of Mechanical Engineering, University of Botswana, Gaborone, Botswana \\ E-mail: \{gandurej, ketloget\}@mopipi.ub.bw \\ Received April 20, 2011; revised May 12, 2011; accepted May 17, 2011
}

\begin{abstract}
The quest for biofuel production and use in Botswana is driven by factors including volatile oil prices, need for fuel security, potential for job creation, potential reduction in greenhouse gas emissions, and economic diversification. In line with national efforts to come up with energy sources that are both environmentally friendly and sustainable, this work was carried out to compare performance properties of native crude marula (Sclerocarya birrea) seed oil and petrodiesel fuel on a variable compression engine test rig with automatic data acquisition set up. Parameters such as engine torque, brake power and specific fuel consumption were measured at different loads for the two fuels. The results indicate that engine performance when powered with crude marula oil compares favourable with those for petrodiesel. Optimum numerical values for engine torque, brake power and specific fuel consumption were $28.2 \mathrm{Nm}, 6.27 \mathrm{~W}$ and $0.34 \mathrm{~g} / \mathrm{kWh}$ respectively for petrodiesel, and $22.7 \mathrm{Nm}, 6.6 \mathrm{~W}, 0.33 \mathrm{~g} / \mathrm{kWh}$ respectively for crude marula oil. The engine performance was also analysed for same parameters, namely, engine torque, brake power and specific fuel consumption when powered using the same fuels over a range of compression ratios while the load was fixed at $80 \%$. Optimum numerical values for engine torque, brake power and specific fuel consumption were $27.2 \mathrm{Nm}, 3.67 \mathrm{~W}$ and $0.59 \mathrm{~g} / \mathrm{kWh}$ respectively for petrodiesel, and $26.3 \mathrm{Nm}, 3.6 \mathrm{~W}, 0.34 \mathrm{~g} / \mathrm{kWh}$ respectively for crude marula oil. The results indicate that compression ratio of 16:1 yields optimum engine performance in terms of engine torque and brake power for both fuels under review. However, marula oil fuel recorded smooth steady increase in performance profile across all compression ratios which out-performs petrodiesel on lower compression ratios for engine torque and brake power, and is largely better than petrodiesel on fuel consumption.
\end{abstract}

Keywords: Performance, Marula Oil, Petrodiesel

\section{Introduction}

The expedition for biofuel production and use in Botswana derives from volatile oil prices, need for fuel security, potential for job creation, potential reduction in greenhouse gas emissions, and economic diversification. The ambition to establish national energy self-reliance and to develop alternatives to finite fossil fuel resources have resulted in the development of fuel technologies that are based on the use of renewable agriculture based materials as feedstocks. In the case of renewable fuels for compression ignition (diesel) engines, the majority of efforts to date have focused on biodiesel, which consists of alkyl esters of fatty acids found in agricultural acylglycerol - based fats and oils. Biodiesel has been shown to give engine performance that is generally comparable to that of conventional diesel fuel while reducing engine emissions of particulates, hydrocarbons and carbon monoxide [1-3]. Biodiesel can be produced from any material that contains fatty acids, bonded to other molecules or present as free fatty acids. As a result various vegetable fats and oils, animal fats, waste greases, and edible oil processing wastes can be used as feedstocks for biodiesel production. The choice of feedstock is based on a number of factors including availability, cost, government support and performance as a fuel [4].

This work sought to establish performance properties of marula oil as a potential feedstock for biodiesel production in Botswana. The results are expected to provide indicators which can be used to stimulate rapid development of biodiesel using indigenous feedstocks in Botswana. Marula tree is indigenous to most parts of the Southern African Development Community. In Botswana, for example, it is widely distributed all over the 
country and concentrated in the north eastern part. The tree grows in warm and dry climatic conditions, and produce oval fruits that turn pale yellow when ripe as demonstrated in Figure 1.

The fruit presented in Figure 1 consists of a hard woody seed covered by pulp and juice which makes the fleshy part of the fruit. The hard seed contains mostly two oil rich nuts (kernel) which can be eaten as a snack. In Botswana the kernel oil is currently being used to make cosmetic ointments. The fact that the marula tree grows in drier parts where common oil seeds cannot thrive has stimulated interest in the use of marula oil as substitute for petroleum diesel fuel. This situation has led to the evaluation of marula nut oil as a potential source of vegetable oil for biodiesel production.

\section{Materials and Methods}

\subsection{Marula Oil}

The crude marula oil under review is sourced from Kgetsi Ya Tsie, a Community Trust whose mandate is to promote economic and social empowerment of rural women in the Tswapong Hills of Eastern Botswana. The Community Trust extracts marula oil mostly for cosmetic markets in Europe and America.

\subsection{Engine Performance Analysis}

The engine performance test was conducted on a variable compression engine test rig. The test rig is water cooled, four-stroke diesel engine that is directly coupled to an electrical dynamometer. In addition to the conventional engine design, the engine incorporates variable compression design features which allow the compression ratio to be varied from 5:1 to $18: 1$.

To ensure that engine operating conditions were reproduced consistently as any deviation could exert an

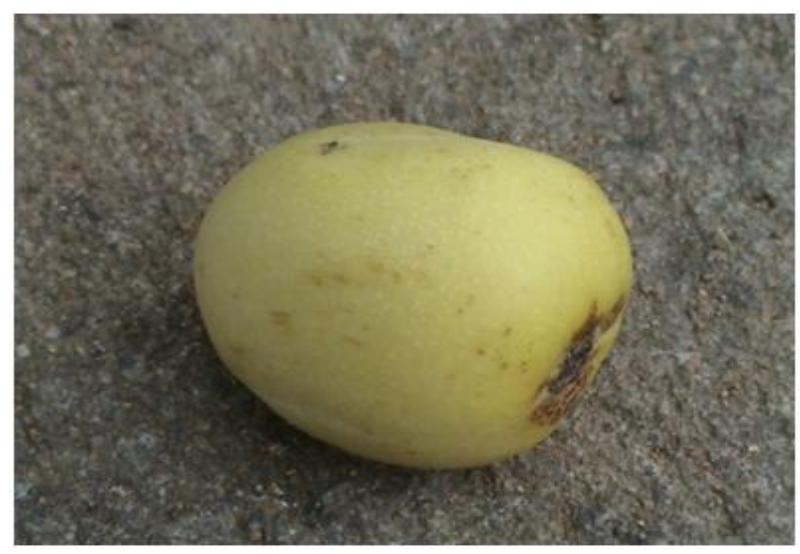

Figure 1. Ripe marula fruit. overriding influence on performance results, the dynamometer speed control set points were maintained within $\pm 4 \mathrm{revs} / \mathrm{min}$ of the desired engine speed. The experimental work began with engine run on D100. This was done to determine the engine's operating parameters which constitute the baseline that was compared with the subsequent case when B100 (crude marula oil applied to function as $100 \%$ biodiesel) was used to run the engine. At the point of fuel change, the engine was allowed to run using the fuel under review for approximately 15 minutes in order to stabilise before readings were recorded.

\section{Results and Discussions}

\subsection{Engine Performance Analysis with Varying Load}

Marula oil was neutralised using $\mathrm{NaOH}$ to remove acidity and minimise corrosion effects on engine parts. The oil was also heated to a temperature of approximately $68^{\circ} \mathrm{C}$ to lower its viscosity and to provide a reaction temperature for faster conversion to biodiesel. The fuel was then used to run a variable compression ignition engine in order to test the engine performance, prior to its transesterification. The results recorded for using raw marula oil were compared with the results for petroleum diesel under similar operating conditions on the basis of engine torque, engine brake power, and specific fuel consumption for compression ratio 16:1. The experimental data were recorded as discussed in section 2.2, leading to the results presented in Figures 2 to 4.

There are several clear findings to be drawn from the data presented in Figures 2 to 4 . Firstly, the results indicate that the engine torque, brake power, and specific fuel consumption recorded for D100 and B100 for operation condition under review (compression ratio 16:1) compares favourably well. The data in Figure 2 show a steady increase in engine torque for D100 and B100 with corresponding increase in engine load from 30 to $60 \%$. However the same data show that between the engine load $30 \%$ to $50 \%$, B100 recoded relatively high engine torque compared with D100. However, the data also depict that as the engine load increase from $60 \%$ the data recorded for D100 shows a steady increase in engine torque while the data for B100 shows a slight decrease with increase in engine load. The profile suggests that the use of raw marula oil as fuel in IC engine gives better engine torque at full engine load.

The results in Figures $\mathbf{3}$ and $\mathbf{4}$ also demonstrate that the data recorded for B100 compares favourably well with that for D100. The maximum variation in brake power of $0.63 \mathrm{~W}$ was recorded at $90 \%$ engine load, while 


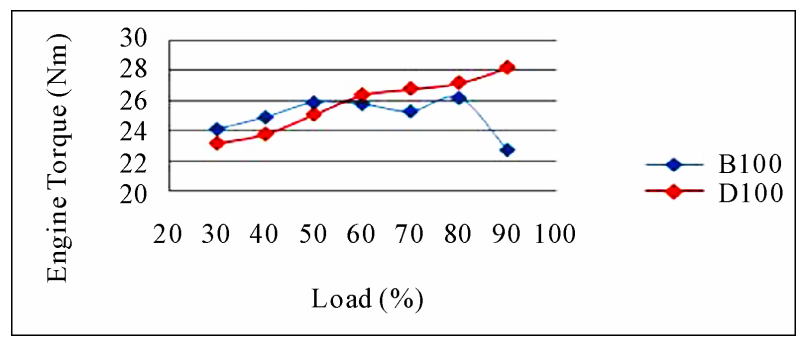

B100 = Marula oil fuel; D100 = Petrodiesel

Figure 2. Engine torque profile for marula oil and petroleum diesel fuel at compression ratio of 16:1.

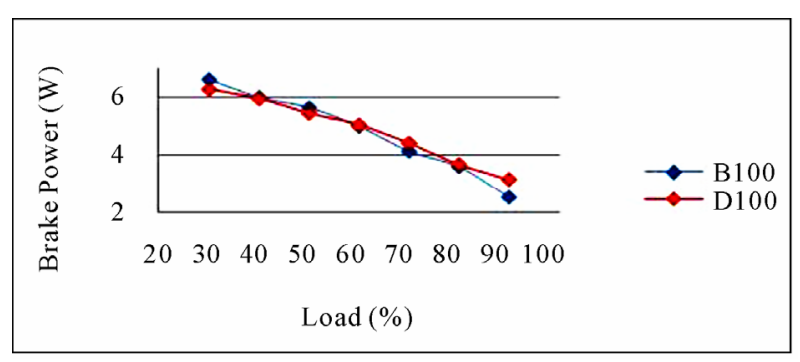

B100 = Marula oil fuel; D100 = Petrodiesel

Figure 3. Engine brake power profile for marula oil and petroleum diesel fuel at compression ratio of 16:1.

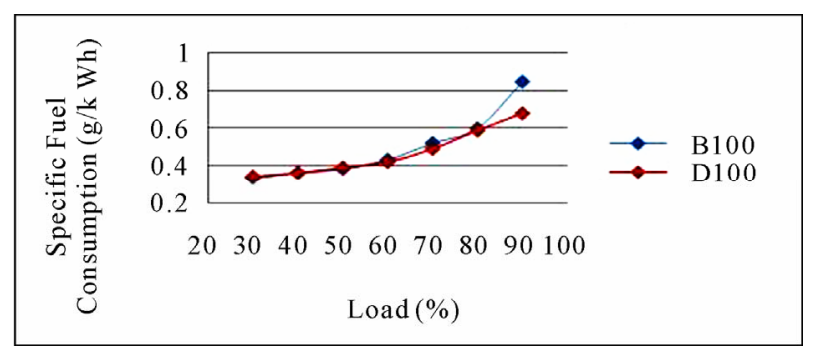

B100 = Marula oil fuel; D100 = Petrodiesel

Figure 4. Engine specific fuel consumption profile for marula oil and petroleum diesel fuel at compression ratio of 16:1.

the minimum variation of $0.06 \mathrm{~W}$ was recorded at $60 \%$ of engine load, with D100 recording $5.06 \mathrm{~W}$. The trends presented in Figure 3 suggest that the optimum compression ignition engine performance using raw marula oil occurs at $60 \%$ engine load. The data shown in Figure 4 for the specific fuel consumption recorded for D100 and B100 reinforces the above observations. One of the most discernible trends connected to Figure $\mathbf{4}$ is that the variations in specific fuel consumption recorded for D100 and B100 between 30\% and 60\% do not show any significant difference for the fuels under review. The minimum variation of specific fuel consumption between $30 \%$ and $60 \%$ engine load is $0.01 \mathrm{~g} / \mathrm{kWh}$, while a maximum of $0.17 \mathrm{~g} / \mathrm{kWh}$ was recorded at the engine load of 90\%. Overally, the result in Figure 4 points out that raw marula oil is a potential feedstock for biodiesel produc- tion in Botswana.

\subsection{Engine Performance Analysis with Varying Compression Ratio}

This section presents results for engine performance at a fixed load of $80 \%$ with compression ratio varying from 13:1 to 17:1. The results are a comparison between D100 and B100. The analysis aims to establish the influence of compression on the engine performance using raw marula oil and compare such trends with those recoded for D100 under similar operating conditions. The experimental data were recorded and results presented in Figures 5 to 7.

The results presented in Figures $\mathbf{5}$ and $\mathbf{6}$ indicate that profiles for engine torque and brake power are largely

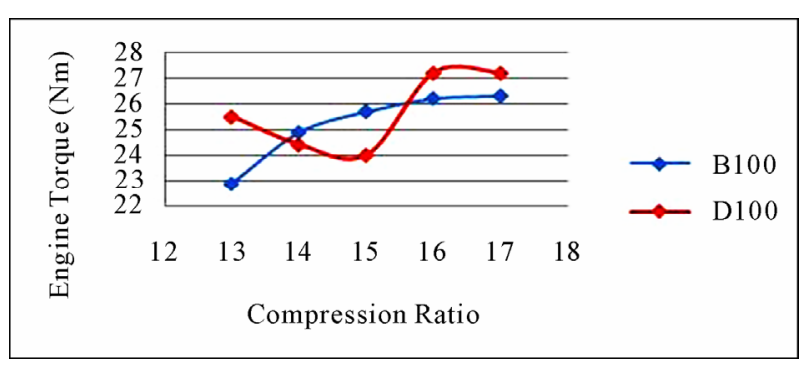

B100 = Marula oil fuel; D100 = Petrodiesel

Figure 5. Engine torque profile for marula oil and petroleum diesel fuel at $80 \%$ load.

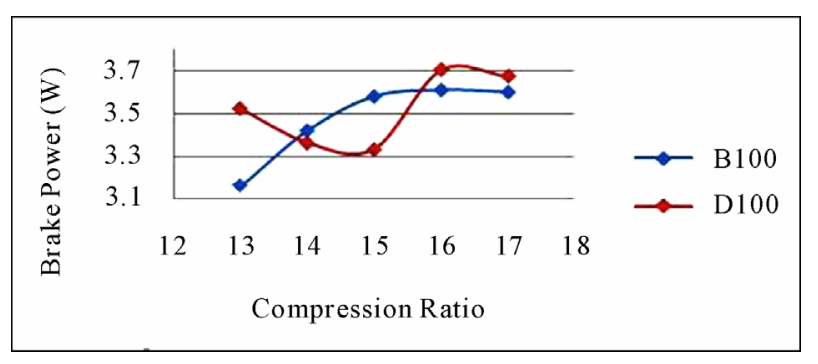

B100 = Marula oil fuel; D100 = Petrodiesel

Figure 6. Engine brake power profile for marula oil and petroleum diesel fuel at $80 \%$ load.

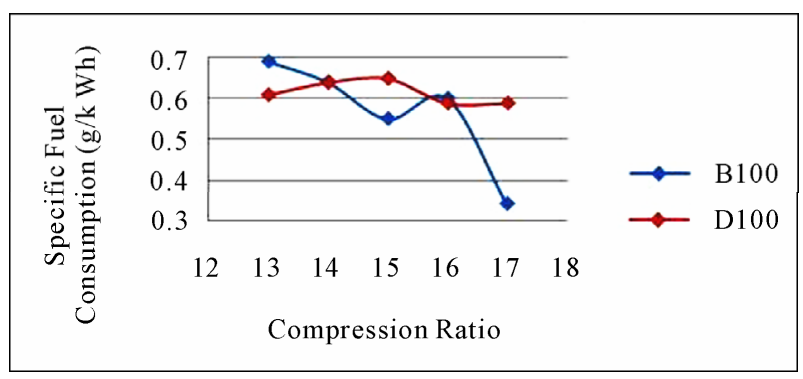

B100 = Marula oil fuel; D100 = Petrodiesel

Figure 7. Engine specific fuel consumption profile for marula oil and petroleum diesel fuel at $80 \%$ load. 
similar. The best performance for marula oil fuel was found to be at compression ratio of 17:1 for engine torque with a value of $26.3 \mathrm{Nm}$, and compression ratio of 16:1 for brake power with a value of $3.61 \mathrm{~W}$. Similarly, best performance for petrodiesel was found to be at compression ratio of 16:1 for both engine torque and brake power with a values of $27.2 \mathrm{Nm} 3.7 \mathrm{~W}$ respectively. These results imply in part that compression ratio 16:1 yields optimum performance results for engine torque and brake power for petrodiesel and marula oil fuels. Petrodiesel is marginally better than marula oil at this compression ratio. For lower compression ratios particularly 14:1 and 15:1, marula oil fuel is significantly better than petrodiesel for both engine torque and brake power. Moreover, unlike petrodiesel, marula oil fuel has a smooth rising performance profile across all compression ratios which suggest smooth running of the engine at any set compression ratio. The results in Figure 7 show that engine specific fuel consumption of marula oil fuel is largely lower than that of petroleum diesel. The fuel consumption at the optimum compression ratio of $16: 1$ is almost the same for the two fuels, with petrodiesel being marginally better by $0.1 \mathrm{~g} / \mathrm{kWh}$.

\section{Conclusions}

A comparative experimental study to analyse the performance of marula oil fuel and petroleum diesel was carried out. From the experimental results, it can be concluded that:

1) Marula oil has properties that enable it to function as a biofuel in variable compression diesel engines. This suggests that transesterifying marula oil under standard conditions should produce biodiesel of international quality standard.

2) Since crude marula oil has proved to perform well as a fuel, it may not be necessary to incur costs through processing the oil to produce biodiesel. Instead, the oil may be modified through additives to enhance performance.

3) The compression ratio of 16:1 yields optimum performance results for engine torque and brake power for petrodiesel and marula oil fuels.

4) The performance of variable compression diesel engine using raw marula oil is close to that using petrodiesel fuel, suggesting that marula oil is a potential indigenous feedstock for biodiesel production in Botswana.

\section{Acknowledgements}

We acknowledge support of the University of Botswana, Kgetsi Ya Tsie Community Trust for providing marula oil, and the Ministry of Wildlife, Tourism and Environment for granting a research permit for this work.

\section{References}

[1] M. S. Graboski and R. L. McCormick, "Combustion of Fat and Vegetable Oil Derived Fuels in Diesel Engines,” Progress in Energy and Combustion Science, Vol. 24, No. 2, 1998, pp. 125-164. doi:10.1016/S0360-1285(97)00034-8

[2] P. M. Adriano, C. T. Richard, M. Luciano, C. Jonas and F. A. Dejanira, "Biodegradability of Diesel and Biodiesel Blends," African Journal of Biotechnology, Vol. 7, No. 9, 2008, pp. 1323-1328.

[3] S.-M. Chen, Y.-J. Huang, S.-C. Chuang and H.-H. Yang, "Effects of Biodiesel Blending on Particulate and Polycyclic Aromatic Hydrocarbon Emissions in Nano/Ultrafine/Fine/Coarse Ranges from Diesel Engine,” Aerosol and Air Quality Research, Vol. 9, No. 1, 2009, pp. 18-31.

[4] M. J. Haas, A. J. McAloon, W. C. Yee and T. A. Foglia, "A Process Model to Estimate Biodiesel Production Costs,” Bioresource Technology, Vol. 97, No. 4, 2006, pp. 671-678. doi:10.1016/j.biortech.2005.03.039 